\title{
BONIFACIO Valentina, Del trabajo ajeno y vacas ariscas. Puerto Casado. Genealogías (1886-2000)
}

\author{
Lorena I. Córdoba
}

\section{OpenEdition}

\section{Journals}

Edición electrónica

URL: https://journals.openedition.org/jsa/18208

DOI: $10.4000 /$ jsa. 18208

ISSN: 1957-7842

Editor

Société des américanistes

\section{Edición impresa}

Fecha de publicación: 30 junio 2020

Paginación: 257-260

ISBN: 978-2-902715-13-8

ISSN: 0037-9174

\section{Referencia electrónica}

Lorena I. Córdoba, «Bonifacio Valentina, Del trabajo ajeno y vacas ariscas. Puerto Casado. Genealogías (1886-2000)», Journal de la Société des américanistes [En línea], 106-1 | 2020, Publicado el 30 junio 2020, consultado el 03 octubre 2022. URL: http://journals.openedition.org/jsa/18208 ; DOI: https:// doi.org/10.4000/jsa.18208

Este documento fue generado automáticamente el 3 octubre 2022.

All rights reserved 


\title{
BONIFACIO Valentina, Del trabajo ajeno y vacas ariscas. Puerto Casado. Genealogías (1886-2000)
}

\author{
Lorena I. Córdoba
}

\section{REFERENCIA}

BONIFACIO Valentina, Del trabajo ajeno y vacas ariscas. Puerto Casado. Genealogías (1886-2000), Centro de Estudios Antropológicos de la Universidad Católica (Biblioteca Paraguaya de Antropología, 108), Asunción, 2017, 321 p., bibliogr., ill. (blanco y negro), photos.

Hay una pregunta fundamental que rodea a todos los documentos, archivos, fotografías y testimonios que compila este libro y que no figura explícitamente en ninguna parte: ¿qué o quién es, exactamente, un "casadeño"? A lo largo de los sucesivos capítulos, Valentina Bonifacio documenta y analiza la memoria de los hombres y mujeres que durante un siglo formaron parte de la empresa de Carlos Casado del Alisal en Paraguay. Carlos Casado S.A. fue una compañía dedicada a la extracción del tanino -procedente de la tala del quebracho colorado-, que se utilizaba para curtir el cuero: una empresa icónica del Paraguay industrial que se asentó en una región inhóspita del Chaco boreal en la cual el ganado cimarrón, las vías del ferrocarril, los quebrachales y los hombres conformaban un "agenciamiento" o conglomerado sociocultural único. De esta forma, "Casado" se transformó en una suerte de categoría polisémica que designaba a un actor económico-social pero también a un tiempo, a un lugar o a un referente ineludible del capitalismo extractivo sudamericano y "casadeño", por tanto, a los protagonistas indígenas y no indígenas de todo un siglo de historia.

2 Sin embargo, el libro no nos propone una mera historia cronológica del auge y caída de una empresa extractiva: analizando los testimonios y la memoria oral de los pobladores (indígenas, criollos, habitantes oriundos o trasplantados por la Guerra del Chaco), pero a la vez completando la información de terreno con una serie de documentos oficiales 
de la empresa, datos procedentes de archivos estatales y privados y una extensa muestra fotográfica que ayuda el lector a situar a los protagonistas en su singular escenario, nos conduce en un colorido recorrido de casi un siglo de historia. Conocedora de la región, de su gente y de los archivos locales, Bonifacio identifica meticulosamente cada uno de los testimonios con nombre y apellido, el puesto y el oficio que cada protagonista ocupaba en la empresa, así como la fecha y el lugar en el que ha llevado a cabo las entrevistas, o bien el idioma en que fueron realizadas.

El primero de los tres grandes apartados del libro traza los contornos del escenario al ubicarnos en el origen, los límites temporales y los confines territoriales que involucran al proyecto general de la empresa Casado. El segundo relaciona a la infraestructura de la empresa -con su puerto, la fábrica, la comisaría, el hotel o la iglesia- con los relatos orales de los protagonistas, inyectando vida en esa topografía. Finalmente, en el tercer apartado, se analiza con mayor detalle el mismo centro operativo de la empresa: el ferrocarril, los obrajes, las estancias o los distintos asentamientos: Kilómetro 11, Kilómetro 40, etc.

4 La autora comienza presentando a Carlos Casado del Alisal. Llegado al Chaco en 1886, su figura etiológica sigue ese prototipo del héroe civilizador que también encontramos en otras regiones extractivas de Sudamérica: Julio César Arana en la Amazonía peruana, Nicolás Suárez en el Beni boliviano o Robustiano Patrón Costas en el noroeste argentino. Nombres legendarios que condensan un imaginario entre folclórico y mítico de esplendor y fortuna, pero a la vez de civilización, de orden y progreso -y a veces, por qué no, también de atropellos, violencia y ambigüedades.

5 Casado gana fama como "el Barón del Chaco", el líder de un emporio de casi seis millones de hectáreas en el Chaco paraguayo. Como otros prohombres extractivos, se trata de una especie de apóstol ferviente de la mecanización: llega a la región con el barco a vapor y especialmente con un ferrocarril que construye en 1901. El ramal ferroviario, de hecho, constituirá la columna vertebral de su imperio recorriendo $160 \mathrm{~km}$ en línea recta de este a oeste y $60 \mathrm{~km}$ hacia el sur, conectando a su vez con otro ramal que se despliega unos $70 \mathrm{~km}$ hacia el norte. Más allá de lo geográfico, esta red constituye la estructura que vertebra a los distintos establecimientos, poblaciones, estancias y secciones de la empresa. Al igual que el tren o el barco de vapor, las máquinas, los puertos, los santos o la iglesia constituyen una materialidad cotidiana que no sólo asocia a la empresa con su territorio, sino que contribuyen a sedimentar en la memoria colectiva las figuras de la familia extensa Casado Sastre, puesto que todo se nombra o se bautiza en relación con alguno de sus miembros -así, por ejemplo, las propias campanas del templo reciben el nombre de las tres hijas de Casado: Margarita, Genara y Casilda.

6 Pero el patriarca fallece en $1899 \mathrm{y}$, como en una novela, su primer heredero es un hijo mayor que será declarado insano. Se constituye entonces una sociedad anónima que nuclea a los herederos, encabezada por el segundo hijo de Casado, José, quien se establece en el Chaco a los 21 años luego de estudiar en Alemania. Los años de José se recuerdan hoy como la época de oro de la firma pues, debido a la necesidad de curtir las botas de los soldados durante la Primera Guerra Mundial, crece exponencialmente la demanda internacional de tanino. En la narrativa polifónica de Bonifacio, la imagen legendaria de José Casado se complementa y contrasta entonces con la información de las fuentes argentinas y paraguayas, con el discurso académico de los historiadores, con los documentos de los misioneros menonitas que le compraban tierras $\mathrm{y}$, 
fundamentalmente, con los recuerdos de los propios trabajadores que lo conocieron como patrón.

7 La Guerra del Chaco (1932-1935) constituye otro pasaje atractivo del relato oral de los casadeños. Casado se encontraba de hecho en el propio centro geográfico del conflicto y "todos recuerdan el fusil que el Mariscal Estigarribia había obsequiado a José Casado -el primer fusil tomado del enemigo- por el apoyo brindado a las tropas paraguayas" (p. 49). Décadas más tarde, el Ministerio de Defensa paraguayo reconoce el papel estratégico de Casado con una medalla especial en mención a su apoyo a las tropas nacionales. Pero, al mismo tiempo, los testimonios orales nos permiten reconstruir la "historia menor" de los trabajadores indígenas durante el conflicto: tanto su participación efectiva en las acciones bélicas como las consecuencias prácticas, bajo la forma principalmente de una serie de relocalizaciones grupales.

8 A continuación, la historia de Casado atraviesa diferentes hitos como la revolución de 1947, la época del doctor Velázquez, la visita de Stroessner en 1968 o la última generación de la familia Casado Sastre a la cabeza de la compañía (que en aquellos años incluía en su árbol genealógico a los Peralta Ramos y a los Cavanagh, apellidos históricos de una no tan lejana Buenos Aires). En 1979 comienza la venta de algunas estancias a la firma Montes y Estancias San José mientras que, casi al mismo tiempo, se inicia la lucha por la tierra de los ex trabajadores indígenas lengua-maskoy que residían en Pueblito junto a la Conferencia Episcopal Paraguaya -contienda legal que finalmente triunfará logrando la titulación de las tierras "Casanillo" en 1981 y "Territorio Riacho Mosquito" en 1987. A comienzos del siglo xxI, la fábrica de tanino está completamente parada: comienzan los retiros voluntarios frente a los rumores de un posible quiebre $y$, ante la amenazante posibilidad de que no se pague nada a los operarios, muchos optan por aceptar una compensación magra por más que deban jubilarse con menos privilegios previsionales de los que les corresponderían por ley. En el año 2000, por fin, entre murmullos, silencios y desinformación, dos bisnietos del fundador llegan a la región a comunicar la venta final de todas las tierras de la familia a la Iglesia de la Unificación, movimiento religioso fundado por el reverendo Moon de Corea del Sur.

9 La era Casado llega, así, a su fin luego de más de cien años de historia. Pero la memoria de sus trabajadores sigue activa, transformándose e incluso cobrando importancia, tal como demuestra la copiosa selección de relatos orales que recoge Bonifacio. En efecto, las pequeñas historias de vida sobre la comisaría, el hotel, el puerto, los obrajes y las estancias se van entretejiendo para regalarnos una mirada vívida de un mundo particular; tan particular, de hecho, que hasta hay un idioma casadeño (sagua'a: vaca arisca, winchi: grúa, linga: cable de acero que ata los haces de quebracho), que sólo encuentra sentido en el seno de la genealogía local. Como el árbol de parentesco de los Buendía, los testimonios compilados en Del trabajo ajeno y vacas ariscas. Puerto Casado. Genealogías (1886-2000) logran evocar un siglo de un Paraguay casi tan sorprendente y singular como el fantástico Macondo. 


\section{AUTORES}

LORENA I. CÓRDOBA

IICS/UCA-CONICET, Argentina 